\title{
Argon 37, Argon 39, and Krypton 81 in the Atmosphere and Tracer Studies Based on These Isotopes
}

\author{
H. H. Loosli, ${ }^{1}$ H. Oeschger, AND W. Wiest \\ Physikalisches Institut, University of Bern, Bern, Switzerland
}

\begin{abstract}
Results of monthly measurements of the tropospheric ${ }^{87} \mathrm{Ar}$ activity during 1969 , as well as measurements of the atmospheric activities of the recently detected isotopes ${ }^{\circledR \mathrm{Ar}}$ and ${ }^{81} \mathrm{Kr}$, are presented. Applications of these isotopes for tracer studies in the atmosphere and in water reservoirs, for the determination of production rates, and for studying the constancy of the cosmic radiation flux are discussed.
\end{abstract}

\section{Measuring Techiniaue}

The measuring technique for ${ }^{87} \mathrm{Ar},{ }^{89} \mathrm{Ar}$, and ${ }^{81} \mathrm{Kr}$ has been described by Loosli and his coworkers [Loosli et al., 1967; Loosli and Oeschger, 1968; Loosli, 1968]. All three isotopes were measured in a proportional counter constructed from a plexiglass tube of 5 -mm wall thickness and 1-liter volume and surrounded by $2 \mathrm{~cm}$ of radioactively pure lead. This counter and inner lead shield were situated in an anticoincidence ring counter, also made of plexiglass, which was filled with $\mathrm{CH}_{4}$ at a pressure of $1 \mathrm{~atm}$. One filling gave satisfactory counting conditions for several months. The outer shielding consisted of $10 \mathrm{~cm}$ of lead; most of the measurements were made in an underground laboratory below 15 meters of rock and soil.

For the argon measurements $2 \%$ of inactive methane was added to the argon and the counter was filled to a pressure of $5.2 \mathrm{~atm}$. For the ${ }^{2} \mathrm{Kr}$ measurements an admixture of $15 \%$ methane gave the best results and satisfactory counting conditions were obtained at pressures up to $3 \mathrm{~atm}$.

The isotopes ${ }^{27} \mathrm{Ar}$ and ${ }^{80} \mathrm{Kr}$ decay by $\mathrm{K}$ capture and subsequent emission of $X$ rays of 2.8 and $13.5 \mathrm{kev}$, respectively, and ${ }^{39} \mathrm{Ar}$ decays by $\beta^{+}$ emission with a maximum energy of $570 \mathrm{kev}$. External energy calibration above $5 \mathrm{kev}$ was possible by irradiation with $\mathrm{X}$ rays and lowenergy $\gamma$ rays through the perspex wall, which

1 Now at Department of Chemistry, University of California at San Diego, La Jolla, California 92037.

Copyright (C) 1970 by the American Geophysical Union. also permitted stability checks of counting conditions during the measurements. Internal calibration for ${ }^{37} \mathrm{Ar}$ in the 3-kev range was provided by an artificial ${ }^{87} \mathrm{Ar}$ sample, and for ${ }^{\circ} \mathrm{Ar}$ by comparing its spectrum with that of ${ }^{85} \mathrm{Kr}$ which had been added to an argon sample.

\section{BACKGROUND}

Argon 37. (35.1 days half-life.) The background in the peak energy range was about 0.08 cpm; the modern net counting rate varied between 0.01 and $0.08 \mathrm{cpm}$. A lower background for X-ray detection could be achieved by using a multiwire grid technique like that recently developed [Wahlen and Oeschger, 1968; Wahlen, 1969].

Argon 39. (269 years half-life.) A background gas for ${ }^{30} \mathrm{Ar}$ was obtained from argon extracted from well gas whose origin is mainly through ${ }^{40} \mathrm{~K}$ decay. The ${ }^{50} \mathrm{Ar}$ content of this well gas argon indicated a contamination with atmospheric argon of less than $1 \%$. The lowest background ( $E=2 \mathrm{kev}$ ) obtained was $1.6 \mathrm{cpm}$ compared with a modern net counting rate of approximately $0.4 \mathrm{cpm}$.

Krypton 81. $\left(2.1 \times 10^{5}\right.$ years half-life.) Detection of $\mathrm{Kr}$ in atmospheric samples is now impossible because of contamination by bomb-produced ${ }^{80} \mathrm{Kr}$. Several measurements were made on a prebomb krypton sample that had a ${ }^{85} \mathrm{Kr}$ activity of less than $0.5 \mathrm{dpm} / 1 \mathrm{Kr}$, resulting in a peak at $13.5 \mathrm{kev}$, due to $X$ rays from ${ }^{81} \mathrm{Kr}$ decay. Since no krypton inactive in ${ }^{a} \mathrm{Kr}$ was available for a background measurement, the net ${ }^{81} \mathrm{Kr}$ activity was based on a background counting rate in the peak range of $0.23 \mathrm{cpm}$, interpolated linearly between the 
counting rates above and below the 13.5 -kev peak. The net ${ }^{\text {st }} \mathrm{Kr}$ counting rate was then 0.08 cpm. Various tests were made to see if the observed peak might perhaps have other causes than the decay of ${ }^{81} \mathrm{Kr}$, but all these tests, mainly attempts to excite the peak with external $X$ rays and $\gamma$ rays, gave negative results [Loosli and Oeschger, 1969].

\section{Results}

Argon 37. The ${ }^{37} \mathrm{Ar}$ measurements are summarized in Table 1. The first sample is from Oakland, California, and was measured by Schell [1968]; the other samples were collected and measured in Bern, Switzerland, having been separated from air under controlled conditions by the Carba AG, Bern. All samples were collected near the ground. For interlaboratory comparison, the same artificial argon sample was measured by Schell and by our group, and agreement within a few per cent was obtained.

Argon 39 . The ${ }^{39} \mathrm{Ar}$ activity was measured in seven atmospheric argon samples extracted in 1940 and between 1959 and 1967 [Loosli and Oeschger, 1968; Loosli, 1968]. The results showed that the contribution from nuclear explosions has been less than $0.005 \mathrm{dpm} / 1 \mathrm{Ar}$. The activity obtained from a first set of measurements was $0.121 \pm 0.005 \mathrm{dpm} / 1 \mathrm{Ar}$, whereas a repetition of these measurements performed some months later gave $0.084 \pm 0.004 \mathrm{dpm} / 1$ Ar. The discrepancy may have been due to contamination of the background well gas argon between the two sets of measurements. In the discussion below we use a value of $0.10( \pm 20 \%)$ dpm/1 Ar.

Krypton 81. About five measurements, made in various counters and shields (both in the cellar of a three story building and in an underground laboratory), gave consistent results with an average value of $0.10( \pm 10 \%) \mathrm{dpm} / 1 \mathrm{Kr}$, based on the background counting rate described earlier [Loosli and Oeschger, 1969].

\section{Production Rates}

The three nuclides ${ }^{97} \mathrm{Ar},{ }^{20} \mathrm{Ar}$, and ${ }^{\text {si }} \mathrm{Kr}$ (mass numbers $\left.A_{\imath}\right)$ are produced primarily by $(n, \gamma)$ reactions in the $1 / v$ energy region on their isotopes of the same element with mass number $A_{i}-1$, and by $n, p$, and $\alpha$ reactions on their isotopes with mass number greater than $A_{i}$. The production rate by the $(n, \gamma)$ process (important only for ${ }^{\mathrm{s}} \mathrm{Kr}$, where there is a large uncertainty in the cross section) was estimated by comparison with the ${ }^{14} \mathrm{C}$ production rate for which we assumed that $2.0 \pm 0.4$ neutrons $/ \mathrm{cm}^{2} /$ sec are captured by ${ }^{14} \mathrm{~N}$. For the reactions on isotopes of higher mass number, we calculated production rates by using the semiempirical cross section formula of Rudstam [1966]. This formula was combined with an atmospheric particle flux calculated by means of a model of secondary particle generation in the atmosphere, which is an extension to higher altitudes of the model of Pal and Peters [1964] for the sea level nucleon flux.

Estimates of the global average production rates by , these two processes are given below for the total atmosphere for ${ }^{80} \mathrm{Ar}$ and ${ }^{81} \mathrm{Kr}$; and, for ${ }^{87} \mathrm{Ar}$ (due to its short half-life), for the troposphere, which is defined here as that part of the atmosphere below the $200-\mathrm{g} / \mathrm{cm}^{2}$ altitude.

Argon 37. For periods of mean solar activity the average tropospheric production rate of ${ }^{87} \mathrm{Ar}$ was calculated as $7.0 \times 10^{-3} \mathrm{dpm} / 1 \mathrm{Ar}$ : $6.5 \times 10^{-s} \mathrm{dpm} / \mathrm{I} \mathrm{Ar}$ by reactions on ${ }^{40} \mathrm{Ar}$ and

TABLE 1. ${ }^{37}$ Ar Measurements on Tropospheric Samples

\begin{tabular}{llll}
\hline \multicolumn{1}{c}{ Date } & Activity, dpm/1 Ar & \multicolumn{1}{c}{ Location } \\
\hline December 12, 1967 & 0.16 & & Oakland, California* \\
February 1, 1969 & 0.023 & $( \pm 15 \%)$ & Bern, Switzerland \\
March 12, 1969 & 0.014 & $( \pm 10 \%)$ & Bern, Switzerland \\
May 20, 1969 & 0.007 & $( \pm 20 \%)$ & Bern, Switzerland \\
June 23, 1969 & $0.0028( \pm 30 \%)$ & Bern, Switzerland \\
July 22, 1969 & 0.0031 & $( \pm 30 \%)$ & Bern, Switzerland \\
October 14, 1969 & $0.0056( \pm 30 \%)$ & Bern, Switzerland \\
November 24, 1969 & $0.089 \quad( \pm 5 \%)$ & Bern, Switzerland \\
December 15, 1969 & 0.035 & $( \pm 9 \%)$ & Bern, Switzerland \\
\hline
\end{tabular}

* Measured by Schell [1968]. 
$0.5 \times 10^{-\mathrm{a}} \mathrm{dpm} / 1 \mathrm{Ar}$ by the ${ }^{30} \mathrm{Ar}(n, \gamma)$ reaction. The corresponding stratospheric value is $6 \times 10^{-2} \mathrm{dpm} / 1 \mathrm{Ar}$. The uncertainty in these values is at least a factor of 2 . The tropospheric value for periods of high solar activity (time of collection of Bern samples) and the estimate given by Lal and Peters [1967] are $5.5 \times 10^{-8}$ and $3.0 \times 10^{-8} \mathrm{dpm} / \mathrm{Ar}$, respectively.

Argon 39. Only reactions on ${ }^{10} \mathrm{Ar}$ are of importance, and the average atmospheric production rate was calculated from our model as $0.10 \mathrm{dpm} / 1$ Ar. Lal and Peters [1967] give the value $0.042 \mathrm{dmp} / 1 \mathrm{Ar}$.

Krypton 81 . An average atmospheric production rate of $0.02 \mathrm{dpm} / 1 \mathrm{Kr}$, resulting from reactions on krypton isotopes with $A>81$, was estimated where about half this value results from the model calculations for incident energy above $100 \mathrm{Gev}$. The production rate by the ${ }^{80} \mathrm{Kr}(n, \gamma)$ reaction was calculated as being either $0.014 \pm 0.003 \mathrm{dpm} / 1 \mathrm{Kr}$ or $0.11 \pm 0.03$ $\mathrm{dpm} / \mathrm{Kr}$, when the two measured cross section values of $12.5 b$ [Reynolds, 1950] and $95 b$ [McNamara and Thode, 1950] were used. Thus the corresponding two values for the total average atmospheric production rate are 0.035 and $0.13 \mathrm{dpm} / \mathrm{Kr}$.

\section{Discussion: Constancy of Cosmic RADIATION}

Argon 39 and krypton 81 . The half-lives of ${ }^{30} \mathrm{Ar}$ and ${ }^{81} \mathrm{Kr}$ are long as compared with atmospheric mixing times, so that their activities should be homogeneous throughout the atmosphere and in equilibrium with their production rates if their production rates have been constant during times of the order of several halflives. On the other hand, past changes in the production rate, and therefore changes in cosmic-ray flux in the atmosphere, would be reflected in differences between present activities and present production rates. Such differences could be much more easily interpreted for the isotopes of argon and krypton than for ${ }^{14} \mathrm{C}$, for example, since argon and krypton isotopes do not mix appreciably with the oceans and other natural reservoirs as does ${ }^{24} \mathrm{C}$. Indeed, less than one per cent of the krypton or argon is dissolved in the oceans. The total inventory on the earth of the radioactive noble gas isotopes produced by cosmic rays is then simply the product of activity and corresponding atmospheric noble gas content. The inventory can be determined much more accurately for the noble isotopes than for ${ }^{14} \mathrm{C}$ because most of the carbon is in the oceans and the oceanic ${ }^{14} \mathrm{C}$ activity distribution is only quite poorly known.

If the values for the production rates could be improved (better particle flux measurements, cross section measurements, and model calculations are necessary) and the ${ }^{81} \mathrm{Kr}$ and ${ }^{80} \mathrm{Ar}$ activities be measured with higher accuracy, then the ratio of present inventories, having been produced during the last several half-lives, and present global production rate could be determined with an accuracy of 10 to $20 \%$. This would lead to really valuable conclusions on the constancy of cosmic radiation during the last $500\left({ }^{80} \mathrm{Ar}\right)$ years and $500,000\left({ }^{85} \mathrm{Kr}\right)$ years, respectively [Oeschger et al., 1970].

At present, however, the production rate estimates are not good enough and the ${ }^{90} \mathrm{Ar}$ and ${ }^{81} \mathrm{Kr}$ measurements are still too inaccurate. For ${ }^{38} \mathrm{Ar}$ the good agreement between production rate and measured activity (both $0.10 \mathrm{dpm} / 1 \mathrm{Ar}$ ) is actually not sufficient for quantitative conclusions on cosmic-ray constancy because of the uncertainties in both numbers. For ${ }^{11} \mathrm{Kr}$ the measured value of $0.10 \pm(10 \%) \mathrm{dpm} / 1 \mathrm{Kr}$ is closer to the production rate based on the higher of the two cross section values. Clearly, in view of the uncertainty in the cross section, no conclusion on cosmic-ray constancy can yet be reached. According to present ideas on the variation of cosmic radiation, it is not impossible that the production rate over roughly the last million years has been a factor of 2 or 3 higher than the present production rate, so that the lower cross section value cannot be ruled out. Thus it is of the greatest importance to obtain a better value for the neutron capture cross section of ${ }^{80} \mathrm{Kr}$. It seems feasible to measure it directly on krypton samples in which the ${ }^{80} \mathrm{Kr}$ is strongly enriched relative to ${ }^{\mathrm{s}} \mathrm{Kr}$, rather than by the indirect techniques based on irradiation of $\mathrm{Br}$ targets as has been done.

Argon 37. Because of the relatively short half-life of ${ }^{37} \mathrm{Ar}$, monitoring its distribution in the atmosphere as a function of latitude, altitude, and time can give information about atmospheric circulation, as well as direct information about the atmospheric distribution of longer-lived isotopes in terms of the constancy of cosmic radiation. 
The realization of this, however, depends on determining the source of the observed ${ }^{87} \mathrm{Ar}$ fluctuations. As seen in Table 1 and Figure 1, the ${ }^{87} \mathrm{Ar}$ concentration of Bern has changed radically during 1969 , having decreased by a factor of about 8 during the first half year and then rapidly increased at the end of the year The November peak is about a factor of 30 above the lowest value (June and July).

Such large fluctuations probably could not have been caused either by natural production rate variations or by sudden injections of ${ }^{87} \mathrm{Ar}$ from the stratosphere. More probable causes include artificial production either by recent atmospheric bomb testing, or by underground nuclear explosions involving the exothermic reaction ${ }^{30} \mathrm{Ca}(n, \alpha)^{37} \mathrm{Ar}$ and subsequent venting, or by specific air cooled reactors. Sampling in altitude profiles is now being planned, and samples are now being collected close to underground testing areas and air-cooled reactors to resolve this question. No data are yet available.

Much more ${ }^{37} \mathrm{Ar}$ is produced by underground nuclear explosions (above reaction) than by atmospheric explosions of comparable size $\left({ }^{36} \mathrm{Ar}(n, \gamma){ }^{87} \mathrm{Ar}\right)$ in which most reaction products go directly into the stratosphere. A possible clue to the true source can be seen in the fact that both observed high values of the ${ }^{37} \mathrm{Ar}$ activity in February and December 1969 are preceded by some underground explosions, whereas in the summer only a few tests were conducted. The U.S. Atomic Energy Commission announced an explosion on December 8, 1968, in low depth, on December 19, 1968, a high-yield explosion, and several tests in October 1969 (e.g., three tests on October 29, 1969). One of these explosions was reported to have released a minor amount of radioactivity in the atmosphere.

Our measurements for the months of June, July, and October 1969 are the lowest ones and are consistent within the error limits. Their average of $0.038 \mathrm{dpm} / 1 \mathrm{Ar}$ is closer to the average global tropospheric production rate given by Lal and Peters $\left(3 \times 10^{-8} \mathrm{dpm} / 1 \mathrm{Ar}\right)$ than ours $\left(5.5 \times 10^{-9} \mathrm{dpm} / \mathrm{Ar}\right)$.

\section{APPLICATIONS}

In addition to studying constancy of cosmic radiation, as discussed above, the potential applications of these noble gas isotopes include their use as tracers in study of the atmosphere, oceans, and ground water and in age determination of ice layers. As tracers, the isotopes have the common advantage that their abundance can be measured relative to their stable isotope rather than relative to the carrier from which they are extracted (e.g., air, water, ice). Results are then much less sensitive to changes in meteorological or geochemical conditions than is the case with, for example, ${ }^{20 \mathrm{Si}}$ or ${ }^{{ }^{20} \mathrm{~Pb}}$.

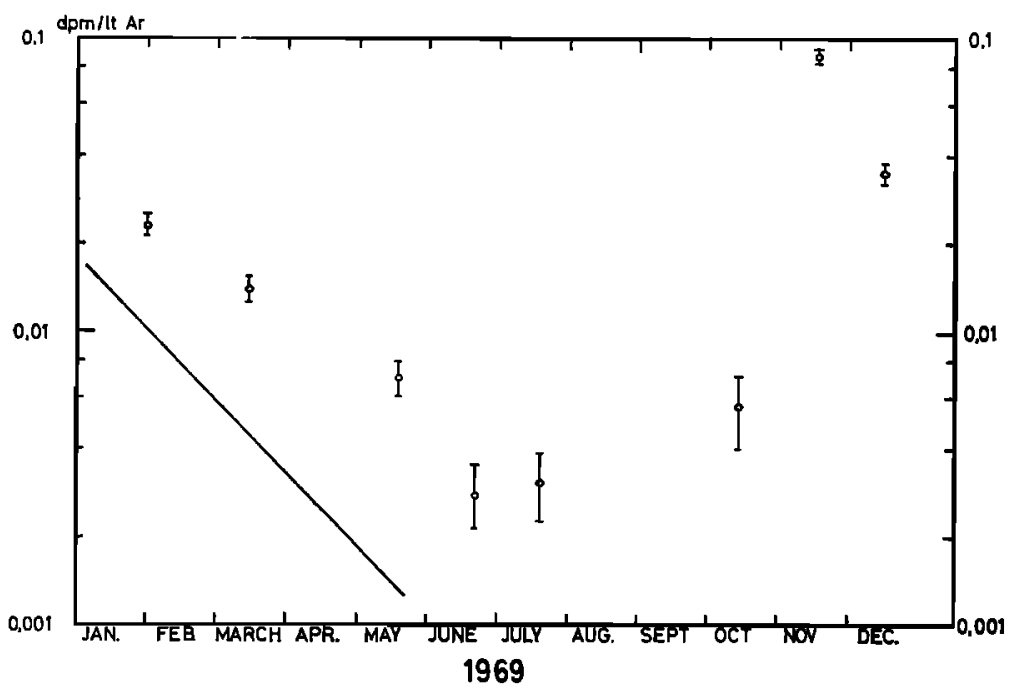

Fig. 1. Isotope ${ }^{\pi} \mathrm{Ar}$ activity at Bern $47^{\circ} \mathrm{N}, 450$ meters altitude; solid line: decay of ${ }^{27} \mathrm{Ar}$ (35.1 days half-life). 
Furthermore, it is not necessary to know the extraction yield, so that uncertainties due to sampling are eliminated. On the other hand, the requirement in some cases of very large samples presents great difficulties.

Argon 37. Applications of ${ }^{87} \mathrm{Ar}$ in atmospheric circulation problems have been discussed by Schell [1970]. In the atmosphere, ${ }^{87} \mathrm{Ar}$ exists in gaseous form and therefore has certain advantages over other cosmic-ray-produced isotopes, such as ${ }^{7} \mathrm{Be}$ and ${ }^{20} \mathrm{P}$, which are carried on aerosols or in some other way less convenient for the study of air movement.

Argon 39. The activity of ${ }^{30} \mathrm{Ar}$, unlike that of ${ }^{24} \mathrm{C}$ and ${ }^{3} \mathrm{H}$, has not increased because of nuclear testing. Whereas ${ }^{14} \mathrm{C}$ and ${ }^{3} \mathrm{H}$ may be used to study the response of reservoirs to varying inputs, ${ }^{\infty} \mathrm{Ar}$ is useful in reflecting the stationary state of such systems. Lal [1963] has pointed out that ${ }^{\infty} \mathrm{Ar}$, due to its chemical inactivity, is a most promising tracer for oceanographic studies. The difficulties of the interpretation in terms of water age of the measured ${ }^{n} \mathrm{C}$ activity has recently become increasingly evident. The isotope ${ }^{20} \mathrm{Ar}$ can also be useful in studying ground water, complementing work using ${ }^{14} \mathrm{C}$ and ${ }^{20} \mathrm{Si}$, since an exchange through the aquifer surfaces can be excluded.

The gas occluded in the ice down to a depth of $\mathbf{5 0 0}$ meters in boreholes at Byrd station, Antarctica, will be extracted during the next few months. Measurements of ${ }^{\circledR} \mathrm{Ar}$ activity are planned to obtain age as a function of depth. Extraction will be accomplished by a technique similar to that developed for ${ }^{14} \mathrm{C}$ from ice [Oeschger et al., 1967] and will require a few tons of ice. For ocean or ground water dating, the argon from about $20 \mathrm{~m}^{8}$ of water is required.

Krypton 81. The dating of ice in coastal areas of Antarctica is an important problem that could be studied by using ${ }^{\text {ec }} \mathrm{Kr}$. To obtain $50 \mathrm{~cm}^{\mathrm{s}}$ of krypton, however, the present minimum volume required, $10^{8}$ tons of ice would be required. The " $\mathrm{Kr}$ in meteoritic $\mathrm{Kr}$ samples has been measured by a mass spectrometer [Eugster et al., 1967], which determined an amount equivalent to less than 1 decay per year. This was possible because the concentrations of neighboring isotopes ${ }^{80} \mathrm{Kr}$ and ${ }^{20} \mathrm{Kr}$ were only $10^{4}$ times higher than the concentration of ${ }^{\mathrm{m}} \mathrm{Kr}$, whereas in the atmosphere this factor is $\sim 2 \times 10^{\mathrm{II}}$. Nevertheless, it seems promising to investigate the development of a technique based on isotopic enrichment and detection by mass spectrometry, sensitive enough for age determination in ice.

Although the studies proposed in this paper are difficult, some perhaps even unrealizable, the real scientific progress to be expected should give us the necessary motivation to overcome these obstacles.

Acknowledgment. This work has been supported by the 'Schweizerischer Nationalfonds.'

\section{REFERENCES}

Eugster, O., P. Eberhardt, and J. Geiss, ${ }^{2} \mathrm{Kr}$ in meteorites and ${ }^{81} \mathrm{Kr}$ radiation ages, Earth Planet. Sci. Lett., 2, 77-82, 1967.

Lal, D., On the investigations of geophysical processes using cosmic-ray produced radioactivity, in Earth Science and Meteoritics, p. 115, NorthHolland, Amsterdam, 1963.

Lal, D., and B. Peters, Cosmic ray produced radioactivity on the earth, in Handbuch der Physik, 46, 551-612, 1967.

Loosli, H. H., Nachweis von ${ }^{2} \mathrm{Ar}$ in atmosphärischem Argon and weitere Grundlagen zu einer Datierungsmethode mit diesem Isotop, Dissertation an der Universität Bern, Bern, 1968.

Loosli, H. H., and H. Oeschger, Detection of ${ }^{\mathrm{Ar}}$ in atmospheric argon, Earth Planet. Sci. Lett., $5,191-198,1968$.

Loosli, H. H., and H. Oeschger, ${ }^{\mathrm{sT}} \mathrm{Ar}$ and ${ }^{\mathrm{s}} \mathrm{Kr}$ in the atmosphere, Earth Planet. Sci. Lett., 7, 67-71, 1969.

Loosli, H. H., H. Oeschger, and M. Wahlen, New attempts in low-level counting and a search for cosmic ray-produced ${ }^{\circledR} \mathrm{Ar}$, in Radioactive Dating Methods of Low-Level Counting, p. 593, International Atomic Energy Agency, Vienna, 1967.

MacNamara, J., and $H$. G. Thode, The relative neutron capture cross sections of the isotopes of krypton and xenon, Phys. Rev., 80, 296-297, 1950.

Oeschger, H., B. Alder, and C. C. Langway, An in situ gas-extraction system to radiocarbon date glacier ice, J. Glaciol., 6, 939-942, 1967.

Oeschger, H., J. Houtermans, H. Loosli, and M. Wahlen, The constancy of cosmic radiation from isotope studies in meteorites and on the earth, in Proceedings of the XII Nobel Symposium, Uppsala, in press, 1970.

Pal, Y., and B. Peters, Meson production at high energies and the propagation of cosmic rays through the atmosphere, Mat.-Fys. Medd. Kgl. Danske Vidensk. Selsk., SS(15), 1964.

Reynolds, J. H., New long-lived krypton activity, Phys. Rev., 79, 886-887, 1950.

Rudstam, G., Systematics of spallation yields, $Z$. Naturforseh., 21a, 1027-1041, 1966.

Schell, W. R., An internal gas proportional 
counter for measuring cosmic ray produced radionuclides, paper presented at 155 th American Chemical Society Meeting, San Francisco, Calif., 1968.

Schell, W. R., Investigation and comparison of radiogenic argon, tritium and carbon-14 in atmospheric reservoirs, in Proceedings of the XII Nobel Symposium, Uppsala, in press, 1970.

Wahlen, M., Aktivierung von kosmischem Material im interplanetaren Raum; messtechnische und experimentelle Beiträge, sowie Modellrechnungen, Dissertation an der Universität Bern, Bern, 1969.

Wahlen, M., and H. Oeschger, High-efficiency $4 \pi-$ proportional low-level counter for X-ray sources, Nucl. Instr. Meth., 66, 193-196, 1968.

(Received November 21, 1969; revised January 16, 1970.) 